\title{
The Role of Molecular Diagnostics in Cancer Diagnosis and Treatment
}

\author{
Luka Ozretić Lukas C. Heukamp Margarete Odenthal Reinhard Buettner \\ Institute of Pathology, University Hospital of Cologne, Germany
}

\author{
Keywords \\ Molecular diagnostics · Lung cancer - EGFR . \\ Next generation sequencing
}

\section{Summary}

The field of molecular diagnostics has improved our understanding of the pathophysiological mechanisms of malignant alteration, especially in lung cancer which remains the leading cause of cancer-related mortality worldwide. The role of the epidermal growth factor receptor (EGFR) and other molecules linked to the EGFR signaling pathway has been extensively studied, and they have become the target of new, specific therapies in lung adenocarcinomas. Similarly, the amplification of the fibroblast growth factor receptor 1 (FGFR1) gene described in squamous cell lung carcinomas has opened new possibilities for molecular targeted therapy. Next generation sequencing (NGS) methods have made possible an even more accurate detection of rare somatic mutations.

\section{Introduction}

Molecular diagnostics methods play an increasingly important role in understanding the pathogenesis of various diseases as well as in their diagnosis and treatment. Analysis of HER2 amplification status in breast cancer and KRAS mutations in colorectal cancer have already been widely accepted as a supplement to conventional histological examination. A big step forward in elucidating tumor pathogenesis was made upon identification of the epidermal growth factor receptor (EGFR) and its role in lung cancer which remains the most common cause of cancer deaths in men and the second leading cause of cancer deaths in women [1]. Molecular analysis of the EGFR, its corresponding downstream signaling cascades, and their mutations has paved the way for novel, molecular targeted cancer therapies, proving that this type of

\author{
Schlüsselwörter \\ Molekulare Diagnostik - Bronchialkarzinom - EGFR . \\ Next-Generation-Sequenzierung
}

\section{Zusammenfassung}

Die molekulare Diagnostik hat unser Verständnis pathophysiologischer Mechanismen maligner Veränderungen verbessert. Dies gilt insbesondere für das Bronchialkarzinom, das weiterhin die weltweit führende Ursache der krebsassoziierten Todesfälle ist. Die Rolle des epidermalen Wachstumsfaktorrezeptors (EGFR) und seiner Signaltransduktionswege wurde ausführlich untersucht und damit Angriffsziele für neue, spezifische Therapien des Adenokarzinoms identifiziert. Ebenso wurde eine Amplifikation des Fibroblasten-Wachstumsfaktor-Rezeptor-1Gens (FGFR1) beim Plattenepithelkarzinom der Lunge beschrieben, womit neue Möglichkeiten für die molekular gerichtete Therapie eröffnet worden sind. Eine präzisere Detektion somatischer Mutationen wird durch die Next-Generation-Sequenzierung ermöglicht.

analysis performed on histological material is becoming increasingly important in cancer diagnostics and patient stratification for therapy.

\section{EGFR in Lung Adenocarcinoma}

The EGFR is a transmembrane tyrosine kinase that belongs to the ErbB family of receptors. It possesses an extracellular, transmembrane as well as intracellular domain, so that binding of the specific ligands, including the epidermal growth factor (EGF), transforming growth factor $\alpha(\mathrm{TGF} \alpha)$, and the neuregulins, induces a series of intracellular signaling cascades [2, 3]. Binding of the ligand to the extracellular domain causes dimerization with other receptor molecules. Both homodimerization with another EGFR receptor and

\section{KARGER \\ Fax +497614520714 \\ Information@Karger.de}

www.karger.com
(C) 2012 S. Karger GmbH, Freiburg

0378-584X/12/3513-0008\$38.00/0

Accessible online at:

www.karger.com/onk
Prof. Dr. med. Reinhard Buettne

Institute of Pathology

University Hospital of Cologne

Kerpener Str. 62, 50937 Cologne, Germany

Tel. +49 221 478-5252, Fax -6360

reinhard.buettner@uk-koeln.de 


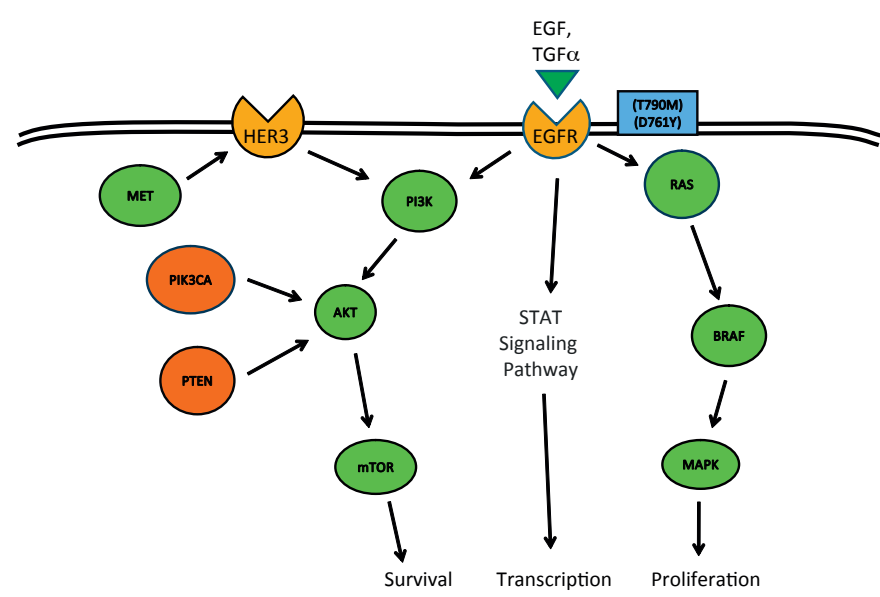

Fig. 1. Signaling pathway mediated by EGFR (simplified).

heterodimerization with other members of the ErbB family are possible. As a result, the receptor undergoes a conformational change with reorientation of the intracellular domain in its activated kinase configuration [3]. The activated EGFR kinase catalyzes phosphorylation of tyrosine residues of other intracellular proteins as well as autophosphorylation of its own C-terminal domain. The phosphorylated EGFR undergoes interactions with several proteins that initiate other signal transduction cascades, among which MAPK, STAT3, and Akt signaling pathways are known for their role in lung cancer pathophysiology [4]. A simplified schematic illustration of the EGFR signaling pathway is shown in figure 1. EGFR is normally expressed in tissues of epithelial, mesenchymal, and neuronal origin [5] and plays an important role in cell differentiation and proliferation [6]. However, it is also involved in cell survival, growth, and metastatic spread $[7,8]$ of various tumors, including head and neck cancer, breast cancer, lung cancer, colorectal cancer, kidney cancer, prostate cancer, ovarian cancer, and glioblastoma multiforme [9]. EGFR overexpression has also been correlated with advanced stages of disease, poor prognosis [10-12], and resistance to radiation, chemotherapy or hormonal therapy $[13,14]$.

\section{Therapeutic Possibilities}

Due to its role in cancer development and progression, EGFR has become a potential target for cancer therapy, and several drugs directed towards it have already been developed. These can be categorized into 2 groups: monoclonal antibody inhibitors and low molecular weight tyrosine kinase inhibitors [15, 16]. Anti-EGFR monoclonal antibodies (cetuximab, matuzumab) bind to the extracellular part of the EGFR. By competitively blocking the ligand-binding domain, they inhibit the ligand-induced activation of the receptor [16, 17]. Low molecular weight EGFR tyrosine kinase inhibitors (gefitinib, erlotinib) reversibly bind to the ATP binding site at the intracellular domain of the EGFR and in- hibit its autophosphorylation, thus blocking the downstream intracellular signal transduction pathways $[18,19]$.

The first biomarker used to test the efficacy of anti-EGFR therapy in cancer treatment was the semiquantitative analysis of EGFR expression by immunohistochemistry. However, most of the studies could not correlate EGFR expression to the clinical efficacy of EGFR antagonists [20, 21]. An increased EGFR gene copy number was demonstrated in nonsmall cell lung cancer (NSCLC), squamous cell carcinoma of the floor of the mouth, and colorectal carcinoma by fluorescence in situ hybridization (FISH) analysis. One of the first reports that correlated the EGFR gene copy number with cetuximab/panitumumab treatment response referred to a cohort of 31 patients with metastatic colorectal cancer [22]. However, the INTEREST (IRESSA Non-small cell lung cancer Trial Evaluating Response and Survival against Taxotere) study could not correlate the EGFR gene copy number with tumor progression or overall survival of patients treated with gefitinib [23].

Sequencing of the EGFR gene and identification of somatic mutations in its tyrosine kinase domain have improved the understanding of these mechanisms. Activating mutations in the EGFR gene have been reported to be associated with hypersensitivity to tyrosine kinase inhibitors in patients with advanced NSCLC [24].

\section{Mutations and Resistance Mechanisms}

EGFR mutations mostly affect exons 18-21 of the EGFR gene. In-frame deletions in exon 19 and a point mutation in exon 21 that leads to substitution at codon 858 (L858R) are most commonly found. A recent study has defined exon 19 deletions or L858R mutations as best predictive factors for time to treatment failure in chemotherapy-naïve NSCLC patients on gefitinib [25]. Sequence analysis of exons 18 and 21 is shown in figure 2 .

Another study involving a larger number of patients with lung cancer [26] has confirmed the importance of screening for EGFR mutations before making decisions about treatment, and has helped to establish molecular analysis of lung adenocarcinoma as a routine in determining the mutation status of a tumor and predicting the response to treatment with EGFR tyrosine kinase inhibitors.

In addition to EGFR mutations, pathogenesis of lung cancer may also involve mutations in other genes of the EGFR signaling pathway. 2 main intracellular pathways activated by EGFR are the RAS/MAPK and PIK3CA/AKT pathway [27]. Mutations in the KRAS gene can be found in $15-36 \%$ of the patients with NSCLC and may lead to an EGFR-independent activation of MAPK [28]. These mutations almost never occur simultaneously with EGFR mutations and are associated with resistance to EGFR tyrosine kinase inhibitors [29]. Similarly, mutations in the BRAF gene activate the EGFR signaling 
Fig. 2. Sequence analysis of exons 18 and 21: A G719A mutation in the EGFR exon 18 results in a substitution of glycine at position 719 for an alanine; $\mathbf{B}$ similar mutations at different positions in exon 21 .
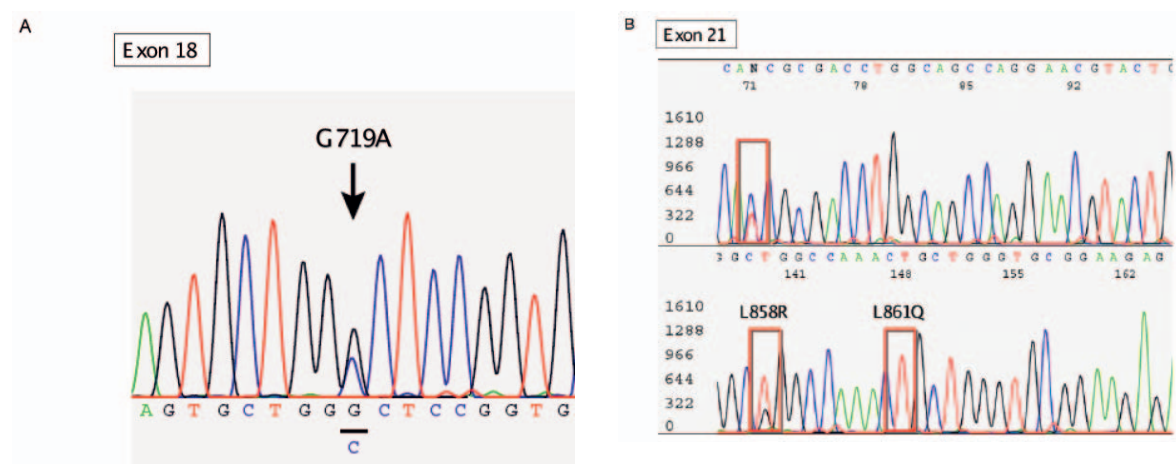

pathway and lead to the development of lung carcinomas with predominantly papillary or bronchioloalveolar growth pattern [30]. Mutations in PIK3CA occur in less than 5\% of patients with lung cancers [31] but may also lead to lower response to EGFR tyrosine kinase inhibitors [32]. Although less commonly, other EGFR pathway genes, including HER2 and HER4, may also be affected by somatic mutations [33].

Another oncogene has been identified in a subset of NSCLC patients, which is the result of fusion of the echinoderm microtubule-associated protein-like 4 gene (EML4) and the anaplastic lymphoma kinase gene (ALK) [34]. Patients who harbor this mutation are more likely to be young men who have never smoked [35]. Histologically, EML4ALK-positive tumors show predominantly a signet ring cell [35] or acinary [36] pattern. The EML4-ALK fusion gene encodes a pathologically hyperactive tyrosine kinase, and these tumors usually lack both EGFR and KRAS mutations [36]. Thus, the patients do not show response to EGFR tyrosine kinase inhibitors and are candidates for treatment with an ALK inhibitor therapy and should be screened for the translocation by FISH [35]. A c-Met/ALK-inhibitor is currently being tested in a phase III clinical trial [37].

Up to $50 \%$ of patients with NSCLC, who initially responded to gefitinib/erlotinib therapy, develop a secondary resistance to treatment, which is mostly due to a substitution of methionine for threonine at codon 790 (T790M) in exon 20 $[38,39]$, leading to a conformational change at the ATP-binding site of the tyrosine kinase that makes binding of the tyrosine kinase inhibitors impossible [40]. This mutation was reported to be detectable in some patients before treatment and correlated with lower survival rates [41]. Other resistance mechanisms include loss of the PTEN tumor suppressor gene with consequent activation of EGFR and Akt [42], as well as amplification of the MET proto-oncogene that leads to HER3-dependent PIK3CA activation [43].

\section{FGFR in Squamous Cell Lung Carcinoma}

In contrast to adenocarcinoma, no specifically targeted therapies have been reported in squamous cell lung carcinoma. However, a focal amplification involving another protein

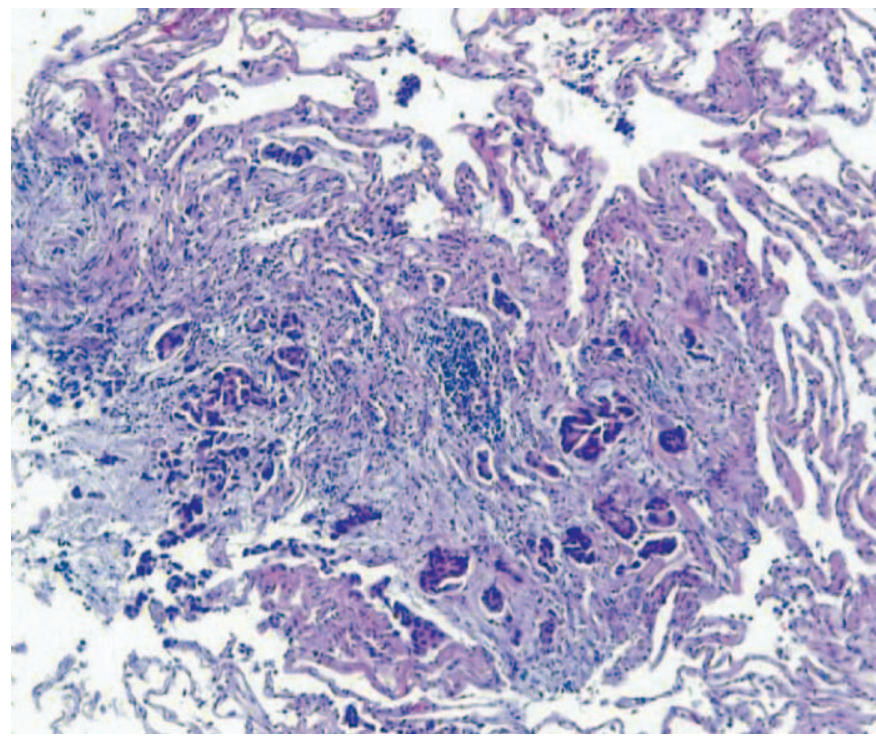

Fig. 3. Lung biopsy. Lung tissue infiltration by an adenocarcinoma.

important for the regulation of cell growth and maturation fibroblast growth factor receptor 1 (FGFR1) - has recently been reported. The studies conducted show that frequent and focal FGFR1 amplification is associated with growth and survival in squamous cell lung cancer [44, 45]. This suggests FGFR1 as a potential target for novel anticancer drugs. Clinical trials with FGFR1 inhibitors are already in progress, including a phase I study that has recently been initiated at the Center for Integrated Oncology (CIO) Cologne Bonn [46].

\section{Current Analyses and Potential Problems}

Currently, most molecular analyses are performed as sequential single assays either based on high resolution melting curve analysis for genes where hotspot mutations are known, i.e. BRAF, KRAS, PIK3CA, or direct standard Sanger sequencing of relevant exons in for example EGFR. At the CIO Cologne Bonn, these analyses are routinely used as part of extended predictive diagnostics. They are all performed on formalin-fixed paraffin-embedded tissues (FFPE) and require 
a relatively high tumor content to allow for mutation detection. Figure 3 shows a representative small lung biopsy infiltrated with an adenocarcinoma used for routine diagnostics. Since the analyses are performed sequentially, results can take up to 3 weeks, which with limited hospital stays may present a significant bottleneck. It is therefore recommended that samples for DNA extraction be prepared in parallel with the conventional HE slides, especially in cases where primary diagnostics are done outside the centre for molecular diagnostics. In summary, there is an urgent need to firstly speed up the molecular pathologic analysis and also to reliably detect low frequency mutations in samples with limited tumor content. The current challenge is to implement next generation parallel sequencing approaches to address both these issues.

\section{New Perspectives by Next Generation Sequencing Technologies}

Since the novel and individualized therapeutic approaches of NSCLC depend on the detection of a wide and increasing panel of somatic mutations in signal transducers, fast and highly sensitive molecular diagnostic tools are required. In the last 5 years, next generation sequencing (NGS) methods have fundamentally changed genomic analyses, providing a more accurate and sensitive detection technology of rare somatic mutations in the tumor $[47,48]$. Though the NGS chemistries are varied reaching from pyrosequencing, to polymerasebased primer extension and iterative oligonucleotide ligation, the strategy in common is the read through many different DNA templates in parallel but in separated flow cells. Thus, millions of sequencing reads of the DNA templates are generated in parallel, gathering information of up to $200 \mathrm{~Gb}$, while the read lengths for each DNA template are very short (35$500 \mathrm{bp}$ ) compared to the traditional Sanger sequencing method [48]. This principle of highly parallel sequencing of single or clonally amplified DNA molecules, each analyzed in a single separate flow cell, enables the analysis of a DNA population with low numbers of mutated DNA molecules against a large background of wild-type DNA.

The parallel sequencing techniques can be applied to a panel of certain relevant genes that are prone to harbor can-
A
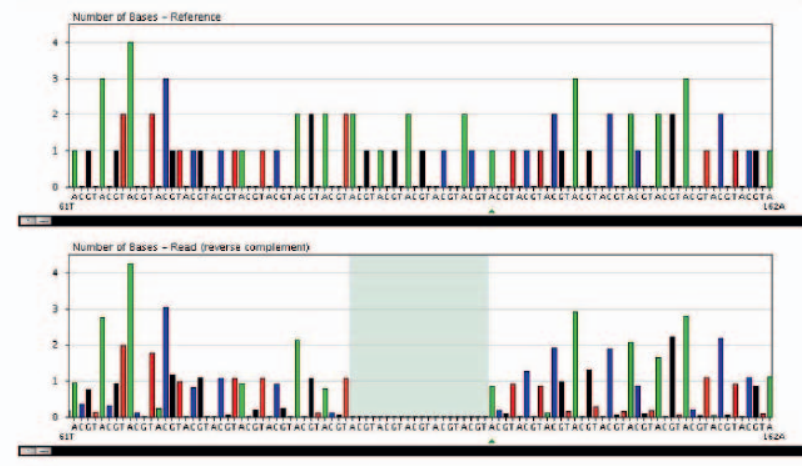

B

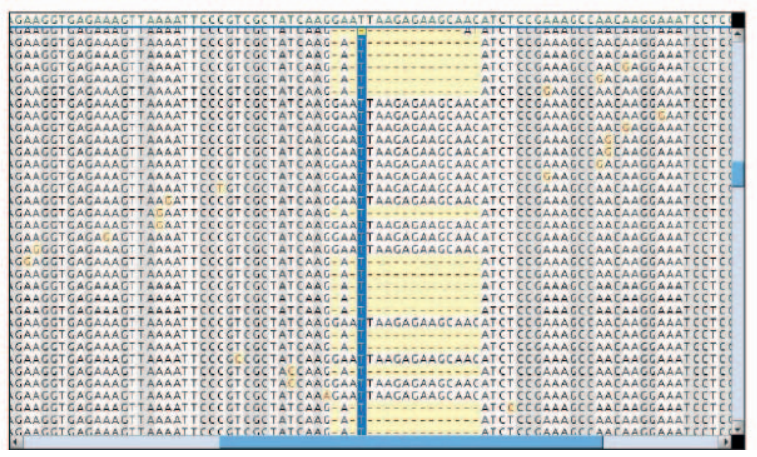

Fig. 4. Data of parallel sequencing showing numerous reads of exon 19 of the EGFR. Next generation sequencing (NGS) data, generated by pyrosequencing and read by the GS Junior (454 Life Sciences/Roche, Branford, CT, USA), were analyzed with Amplicon Variant software (454 Life Sciences/Roche). A The deletion in exon 19 of the EGFR gene is shadowed in the pyrosequencing flow diagram. B Multiple reads $(n>600)$ of the exon 19 locus revealed in approximately $50 \%$ of the sequences a deletion in exon 19 of the EGFR gene.

cer-specific point mutations or deletions (fig. 4), but also to a comprehensive assortment of signal transducers involved in signaling of tumor cells, or even to the entire transcriptome, exome, or genome of the tumor cells. These perspectives will take center stage in the identification of novel genetic cancer markers and in future molecular diagnostics supporting an improved personal therapy of the patient [49].

\section{Disclosure Statement}

The authors declare no conflicts of interest.

\section{References}

1 Jemal A, Center MM, DeSantis C, Ward EM: Global patterns of cancer incidence and mortality rates and trends. Cancer Epidemiol Biomarkers Prev 2010;19:1893-907.

2 Burgess AW: EGFR family: structure physiology signalling and therapeutic targets. Growth Factors 2008;26:263-74.

-3 Roskoski R Jr: The ErbB/HER receptor protein tyrosine kinases and cancer. Biochem Biophys Res Commun 2004;319:1-11.
4 Akca H, Tani M, Hishida T, et al.: Activation of the AKT and STAT3 pathways and prolonged survival by a mutant EGFR in human lung cancer cells. Lung Cancer 2006;54:25-33.

5 Yano S, Kondo K, Yamaguchi M, et al.: Distribution and function of EGFR in human tissue and the effect of EGFR tyrosine kinase inhibition. Anticancer Res 2003;23:3639-50.
6 Yarden Y, Schlessinger J: Epidermal growth factor induces rapid, reversible aggregation of the purified epidermal growth factor receptor. Biochemistry 1987;26:1443-51.

7 Sobol RE, Astarita RW, Hofeditz C, et al.: Epidermal growth factor receptor expression in human lung carcinomas defined by a monoclonal antibody. J Natl Cancer Inst 1987;79:403-7. 
8 Ciardiello F, Tortora G: A novel approach in the treatment of cancer: targeting the epidermal growth factor receptor. Clin Cancer Res 2001; 7:2958-70.

9 Stoscheck CM, King LE Jr: Role of epidermal growth factor in carcinogenesis. Cancer Res 1986; 46:1030-7.

10 Woodburn JR: The epidermal growth factor receptor and its inhibition in cancer therapy. Pharmacol Ther 1999;82:241-50.

11 Salomon DS, Brandt R, Ciardiello F, Normanno N Epidermal growth factor-related peptides and their receptors in human malignancies. Crit Rev Oncol Hematol 1995;19:183-232.

12 Porebska I, Harlozinska A, Bojarowski T: Expression of the tyrosine kinase activity growth factor receptors (EGFR, ERB B2, ERB B3) in colorectal adenocarcinomas and adenomas. Tumour Biol 2000;21:105-15.

-13 Chen Z, Ke LD, Yuan XH, Adler-Storthz K: Correlation of cisplatin sensitivity with differential alteration of EGFR expression in head and neck cancer cells. Anticancer Res 2000;20:899-902.

14 Akimoto T, Hunter NR, Buchmiller L, et al.: Inverse relationship between epidermal growth factor receptor expression and radiocurability of murine carcinomas. Clin Cancer Res 1999;5:2884-90.

15 Normanno N, Bianco C, De Luca A, et al.: Targetbased agents against ErbB receptors and their ligands: a novel approach to cancer treatment. Endocr relat cancer 2003;10:1-21.

16 Harari PM: Epidermal growth factor receptor inhibition strategies in oncology. Endocr Relat Cancer. 2004;11:689-708.

17 Kollmannsberger C, Schittenhelm M, Honecker F, et al.: A phase I study of the humanized monoclonal anti-epidermal growth factor receptor (EGFR) antibody EMD 72000 (matuzumab) in combination with paclitaxel in patients with EGFR-positive advanced non-small-cell lung cancer (NSCLC). Ann Oncol 2006;17:1007-13.

18 Anderson NG, Ahmad T: ErbB receptor tyrosine kinase inhibitors as therapeutic agents. Front Biosci 2002;7:d1926-40.

19 Mendelsohn J, Baselga J: Status of epidermal growth factor receptor antagonists in the biology and treatment of cancer. J Clin Oncol 2003;21:2787-99.

20 Galizia G, Lieto E, De Vita F, et al.: Cetuximab, a chimeric human mouse anti-epidermal growth factor receptor monoclonal antibody, in the treatment of human colorectal cancer. Oncogene 2007;26: 3654-60.

21 Saltz L, Rubin M, Hochster H, et al.: Cetuximab (IMC-C225) plus irinotecan (CPT-11) is active in CPT-11-refractory colorectal cancer (CRC) that expresses epidermal growth factor receptor (EGFR). Proc Am Soc Clin Oncol 2001;20:abstr 7.
22 Moroni M, Veronese S, Benvenuti S, et al.: Gene copy number for epidermal growth factor receptor (EGFR) and clinical response to antiEGFR treatment in colorectal cancer: a cohort study. Lancet Oncol 2005;6:279-86.

23 Perez-Soler R, Chachoua A, Hammond LA, et al.: Determinants of tumor response and survival with erlotinib in patients with non-small cell lung cancer. J Clin Oncol 2004;22:3238-47.

24 Pao W, Miller V, Zakowski M, et al.: EGF receptor gene mutations are common in lung cancers from 'never smokers' and are associated with sensitivity of tumors to gefitinib and erlotinib. Proc Natl Acad Sci U S A 2004;101:13306-11.

25 Yang CH, Yu CJ, Shih JY, et al.: Specific EGFR mutations predict treatment outcome of stage IIIB/ IV patients with chemotherapy-naive non-smallcell lung cancer receiving first-line gefitinib monotherapy. J Clin Oncol 2008;26:2745-53.

26 Rosell R, Moran T, Queralt C, et al.: Screening for epidermal growth factor receptor mutations in lung cancer. N Engl J Med 2009;361:958-67.

27 Krasinskas AM: EGFR signaling in colorectal carcinoma. Patholog Res Int 2011;2011:932932.

28 Marchetti A, Milella M, Felicioni L, et al.: Clinical implications of KRAS mutations in lung cancer patients treated with tyrosine kinase inhibitors: an important role for mutations in minor clones. Neoplasia 2009;11:1084-92.

29 Ahrendt SA, Decker PA, Alawi EA, et al.: Cigarette smoking is strongly associated with mutation of the K-ras gene in patients with primary adenocarcinoma of the lung. Cancer 2001;92:1525-30.

30 Yousem SA, Nikiforova M, Nikiforov Y: The histopathology of BRAF-V600E-mutated lung adenocarcinoma. Am J Surg Pathol 2008;32:1317-21.

31 Yamamoto H, Shigematsu H, Nomura M, et al.: PIK3CA mutations and copy number gains in human lung cancers. Cancer Res 2008;68:6913-21.

32 Carcereny E, Molina MA, Sanchez JJ, et al.: Mutations of the catalytic subunit a of PI3K (PIK3CA) in erlotinib-treated non-small cell lung cancer (NSCLC) patients (p) with epidermal growth factor receptor (EGFR) mutations. J Clin Oncol 2011;29(suppl):abstr 7588.

33 Gandhi J, Zhang J, Xie Y, et al.: Alterations in genes of the EGFR signaling pathway and their relationship to EGFR tyrosine kinase inhibitor sensitivity in lung cancer cell lines. PLoS ONE 2009;4:e4576.

34 Soda M, Choi YL, Enomoto M, Takada S, et al.: Identification of the transforming EML4-ALK fusion gene in non-small-cell lung cancer. Nature 2007;448:561-6.

35 Shaw AT, Yeap BY, Mino-Kenudson M, et al.: Clinical features and outcome of patients with nonsmall cell lung cancer who harbor EML4-ALK. J Clin Oncol 2009;27:4247-53.
36 Inamura K, Takeuchi K, Togashi Y, et al.: EML4ALK lung cancers are characterized by rare other mutations, a TTF-1 cell lineage, an acinar histology, and young onset. Mod Pathol 2009;22:508-15.

37 Pfizer: Phase 2, open-label single arm study of the efficacy and safety of PF-02341066 in patients with non-small cell lung cancer harboring a translocation or inversion event involving the anaplastic lymphoma kinase (ALK) gene; in ClinicalTrials. gov. Bethesda (MD), National Library of Medicine (US), 2000 (cited 2011 Sept 09); available from //clinicaltrials.gov/ct2/show/NCT00932451, identifier NCT00932451.

38 Kobayashi S, Boggon TJ, Dayaram T, et al.: EGFR mutation and resistance of non-small cell lung cancer to gefitinib. N Engl J Med 2005;352:786-92.

39 Sharma SV, Bell DW, Settleman J, Haber DA: Epidermal growth factor receptor mutations in lung cancer. Nat Rev Cancer 2007;7:169-81.

40 Yun CH, Boggon TJ, Li Y, et al.: Structures of lung cancer-derived EGFR mutants and inhibitor complexes: mechanism of activation and insights into differential inhibitor sensitivity. Cancer Cell 2007; 11:217-27.

41 Maheswaran S, Sequist LV, Nagrath S, et al.: Detection of mutations in EGFR in circulating lung-cancer cells. N Engl J Med 2008;359:366-77.

42 Sos ML, Koker M, Weir BA, et al.: PTEN loss contributes to erlotinib resistance in EGFR-mutant lung cancer by activation of Akt and EGFR. Cancer Res 2009;69:3256-61.

43 Engelman JA, Zejnullahu K, Mitsudomi T, et al.: MET amplification leads to gefitinib resistance in lung cancer by activating ERBB3 signaling. Science 2007;316:1039-43.

44 Weiss J, Sos ML, Seidel D, et al.: Frequent and focal FGFR1 amplification associates with therapeutically tractable FGFR1 dependency in squamous cell lung cancer. Sci Transl Med 2010;2: $62 \mathrm{ra93}$.

45 Dutt A, Ramos AH, Hammerman PS, et al.: Inhibitor-sensitive FGFR1 amplification in human non-small cell lung cancer. PLoS One 2011; 6:e20351.

46 Novartis Pharmaceuticals: A phase I, open-label, multi-center, dose escalation study of Oral BGJ398, a Pan FGF-R kinase inhibitor, in adult patients with advanced solid malignancies; in ClinicalTrials.gov. Bethesda (MD), National Library of Medicine (US), 2000 (cited 2011 Sept 09); available from //clinicaltrials.gov/ct2/show/ NCT01004224, identifier NCT01004224.

47 Morozova O, Marra MA: Applications of nextgeneration sequencing technologies in functional genomics. Genomics 2008;92:255-64.

48 Natrajan R, Reis-Filho JS: Next-generation sequencing applied to molecular diagnostics. Expert Rev Mol Diagn 2011;11:425-44.

49 Bell DW: Our changing view of the genomic landscape of cancer. J Pathol 2010;220:231-43. 